\title{
Cinema = Cavação. Cendroswaldo produções cinematográficas
}

Carlos Augusto Calil 
"Esta vida ativa, cinema e finanças, não era para me desagradar." Moravagine, Pro domo [OCD2: 438].

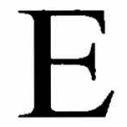

m 1957, no corpo de um livro de escritos díspares reunidos sob a divisa Trop, c'est trop, ("É demais, demais") aparecia um texto que chamou imediatamente a atenção dos leitores brasileiros de Cendrars pela promessa formulada já no seu título: "Etc..., etc... (Un film 100\% brésilien)" [OCD8: 196-200].

Nele, descreve os percalços da produção de um filme no Brasil, que havia tentado realizar no decênio de 1920 . Eis os principais pontos da anedota. Cendrars, personagem de sua autoficção, não tinha vindo ao Brasil para rodar um filme, nem sequer queria ouvir falar de cinema. Mas foi arrebatado pela beleza do país. Decide então fazer um filme para mostrar a floresta, os rios gigantes e o homem que aqui chega para construir-se uma nova pátria. Concebido como um grande filme de propaganda, contaria a história da formação do país, dos pioneiros da colonização aos modernos engenheiros que promoviam o progresso. Os amigos se interessam pelo projeto e acabam por levá-lo a uma entrevista no Palácio do Catete com o presidente da República. O cineasta diz ao mandatário que ama o povo simples do país, alegre e angelical. E que havia inclusive adquirido uma floresta, não para explorá-la, mas para estabelecer um vínculo e propiciar seu retorno freqüente. $O$ filme, embora de propaganda, não deveria ser aborrecido, cheio de estatísticas, e sim um grande documentário, que revelasse o país aos próprios brasileiros: "um filme $100 \%$ nacional". Como não havia artistas nem estrelas no Brasil, os atores principais seriam a natureza e a luz, e os personagens principais, a floresta e o rio Tietê, cuja navegação possibilitou aos paulistas se 
apropriarem do interior, criando a nação brasileira. Advertido por um amigo que o próprio presidente (Washington Luís) era autor de uma tese histórica sobre uma família, pede-lhe autorização para utilizá-la como argumento de seu filme. Obtido o consentimento, dedica-se ao roteiro, enquanto expede telegramas aos EUA e Europa para consulta aos técnicos especialistas. À noite, no hall do Copacabana Palace, onde se hospedava, encontra-se com caçadores, mateiros, exploradores -índios e brancos- para discutir as melhores locações e a sua logística. Com o apoio de um grande jornal de São Paulo, promove concurso de fotogenia, visando à escolha do casal de atores. O presidente do Estado era nessa época Carlos de Campos, um músico erudito a quem pede para compor a trilha de seu filme. $\mathrm{O}$ projeto adquire tais proporções que um banco inglês oferece-lhe crédito de 150 milhões de francos. Capitalistas brasileiros pressionam para participar do empreendimento. Chamado ao ministério da Fazenda, é obrigado a aceitar, a título de propaganda, soma equivalente à oferecida pelo banco. Cendrars sai da sede do ministério com sua carta de crédito e é recebido com tiros de fuzil. A revolução ganhava as ruas. A única coisa que não havia previsto no filme liquidava o seu belo projeto.

Num procedimento comum na sua obra, Cendrars data o seu texto de 1925 , embora o tenha escrito e publicado pela primeira vez em 1929, em Cinémonde, uma revista de cinema.

A datação arbitrária provoca no leitor brasileiro' ${ }^{1}$ um desconforto que os mais curiosos acabam por investigar. Encontram no texto incongruências históricas que desviam a atenção das suas virtudes literárias. A mais evidente é a presença de Washington Luís no Catete em 1925, o presidente que havia tomado posse em 26! A revolução que o derruba é a de 1930 . No entanto, Carlos de Campos era presidente do estado de São Paulo em 1924, quando irrompeu a revolução de julho, liderada pelo general Isidoro Dias Lopes. Autor

1. Cf. BROCA, Brito. "As estórias brasileiras de Blaise Cendrars" (1957) e MARTINS, Wilson. "Cendrars e o Brasil" (1960), ambos reproduzidos em EULALIO, Alexandre, A Aventura Brasileira de Blaise Cendrars, São Paulo; Brasília, Quiron; INL, 1978, pp. 204-7; 215-22. 
de tal imbroglio, Cendrars passa por distraído, fabulista. Suas imprecisões são, no entanto, deliberadas ${ }^{2}$ e, como num painel expressionista, ressaltam a natureza privilegiada das relações de interesses num regime político fechado. Nesse sentido, Alexandre Eulalio deixou uma aguda nota manuscrita:

Nada mais fiel ao espírito da república oligárquica do que esse filme monstro no qual o presidente da República escreve (ou fornece o argumento) e o presidente do Estado de São Paulo, a música, o ministério das Finanças, os fundos etc. etc. Em ritmo de opereta, é uma genial caricatura do sistema de relações da velha República. ${ }^{3}$

Vamos agora aos fatos, à crônica dos pequenos -e grandesacontecimentos em torno da primeira viagem de Blaise ao Brasil. Em carta à família, escrita às vésperas de embarcar no Formose, Cendrars informa:

Parto para a América do Sul... me propuseram diferentes negócios que vou estudar in loco, sendo um de cinema que pode ser muito interessante. ${ }^{4}$

Em $1^{\circ}$ de junho de 1924, encaminhava a Paulo Prado o projeto de um "Grande filme de propaganda do Brasil", resultado de conversas com Oswald de Andrade e o próprio Prado, a quem pede sugestões e o aval para continuar o negócio. $O$ documento inédito, em seguida reproduzido na sua íntegra, já mereceu comentário num colóquio realizado em Paris em 1987.5

2. Em outro texto, "L'actualité de demain", do volume Histoires vraies [OCD3: 41936], BC demonstra melhor memória: ainda que a revolução de julho de 1924 tenha sido por ela transferida para setembro, o presidente era "Bernadès" e o general insurgente "Isodoro". W. Luís ai aparece como presidente em 1926, no inicio do mandato que não concluirá.

3. Centro de Documentação Cultural Alexandre Eulalio, Instituto de Estudos da Linguagem, Unicamp, documento Pc 524, P 74.

4. CENDRARS, Miriam. Blaise Cendrars. Paris: Balland, 1984, p. 387.

5. Cf. ROIG, Adrien, "Blaise Cendrars et le Brésil: le Grand film brésilien, la traduction de A selva, le 'Morro Azul' et la 'Tour Eiffel sidérale' ", atas do colóquio Portugal Brésil France Histoire et culture, Paris: Fondation Calouste Gulbenkian, 1988, pp. 273-98. Nesse texto, o autor desfaz a trapalhada histórica e resume o projeto de Cendrars. 
Para espanto dos intelectuais que o hospedavam, Cendrars evitava falar de literatura, ${ }^{6}$ mas não se negava quando o assunto era cinema. Rubens Borba de Morais relata que, no período que passou em São Paulo em 1924, íamos muito ao cinema. Depois do espetáculo, em bares alemães de Santa Efigênia, bebendo cerveja, [BC] contavanos estórias mirabolantes do tempo em que trabalhava com Abel Gance, filmando La Roue. Inventava roteiros de filmes sobre a vida brasileira que dariam uma fortuna. Cendrars estava imaginando fazer grandes negócios. ${ }^{7}$

As histórias cinematográficas de Cendrars não impressionaram apenas Rubens Borba. Alcântara Machado num exemplar de seu 'livro de cinema' Pathé-Baby escreverá a dedicatória: "Para Blaise Cendrars - grande especialista em fitas de documentação -, com o entusiasmo do Alcântara". 8

A revolução de 5 de julho de 1924 surpreende a todos, população e governo. Diante da violência dos ataques dos revoltosos, que bombardeavam o Palácio do Governo e os bairros operários, Paulo Prado decide refugiar-se na fazenda Santa Veridiana para onde leva seu hóspede. Apartado involuntariamente do espetáculo militar, Cendrars ia com freqüência à cidade de Santa Cruz das Palmeiras para ler nos jornais da capital as últimas novidades revolucionárias.

6. "Essa história dos que atacam a literatura e são literatíssimos é muito cômica. Eu já observara isso quando o Cendrars esteve aqui. Homem pourri de literatura e que vive a maldizer dela. O defeito pegou. [...] Cendrars que dizia e não cumpria, cheio de fachadas e de lembranças, fez mais mal aqui do que bem. A culpa não é tanto dele. É da feminilidade da nossa gente. Se entregaram e vivem agora a imitá-lo. Os fortes não. Veja o Couto [de Barros] que continua calmo na sua rota sem se importar com ninguém. Veja Tarsila que resolveu o problema dela e vai indo prá frente. Mas o Rubens [Borba de Morais] por exemplo está se perdendo. O Osvaldo também que caiu em admiração idiota por tudo quanto é brasileiro e vive a se insurgir contra a erudição e pregando analfabetismo. E uma pena. Eu, ninguém precisou de me vir dizer que o Brasil era interessante." Carta de Mário de Andrade a Sérgio Milliet em Paris, de 10/12/24. DUARTE, Paulo. Mário de Andrade por Ele Mesmo. São Paulo: Edart, 1971, p. 301.

7. MORAIS, Rubens Borba de. "Recordações de Blaise Cendrars", José, Rio de Janeiro, dezembro de 1977, no 9, p. 44.

8. Biblioteca pessoal do escritor, Fonds Blaise Cendrars, Archives Littéraires Suisses, Bibliothèque Nationale Suisse, Berna. 
O projeto do filme ficou assim naturalmente suspenso. Em novembro do mesmo ano, já de volta à sua vidinha no Tremblay-surMauldre, Cendrars dirá na primeira carta que dirige a Paulo Prado:

Filme de propaganda brasileiro. Pouco cuidei deste assunto. De qualquer modo, sondei em duas direções diferentes; os dois lados acharam o negócio muito interessante e estão dispostos a participar com metade do capital, segundo meu orçamento, ou mesmo com a sua totalidade. Diga-me se este é o momento certo de tocar o negócio ou se é melhor esperar ainda um pouco. Um é a Pathé, que daria a metade, e o outro o Banco Mundial (o truste Stinnes) que entraria eventualmente com tudo. Diga a Oswald que continuo esperando o esboço de um roteiro. ${ }^{9}$

Em fevereiro do ano seguinte, depois de concluir $L$ 'Or, Cendrars volta a farrear com os abonados amigos brasileiros em temporada parisiense, entre eles Oswald e Washington Luís. O projeto do filme retorna à mesa, embora ele tenha perdido o controle sobre $o$ assunto.

Não creio que eu vá [ao Brasil] antes da sua partida [de Paulo Prado]. Pois se estou empenhado nesse negócio de cinema, faria ainda mais questão de vê-lo. Mesmo porque aqui Oswald embrulhou tudo de uma maneira inextricável, com Washington [Luís], um banqueiro belga e os seus próprios negócios, que já não entendo mais nada. Oswald segue no fim do mês, você o verá e talvez compreenda onde ele quer chegar. ${ }^{10}$

9. Carta de BC a PP de 22/11/24. Fonds Blaise Cendrars, Berna.

10. Carta de $7 / 4 / 25$. Numa carta a Tarsila, de $25 / 6 / 25$, escrita a bordo do Avon, Oswald revela seu empenho em tornar-se um bem sucedido poeta capitalista: "Comunico-lhe que entrei em relações com um grupo mais forte ainda do que o que tem negócios comigo. Horizontes vastos graças a Deus me preocupam. Passo os dias conversando 'business'. Você sabe inglês, não? Enfim, sou um puro homem de negócios. No entanto, fiz um poema sobre Recife...". AMARAL, Aracy A. Tarsila Sua Obra e Seu Tempo. São Paulo: Perspectiva; Edusp, 1975, p 169. 
Essa foi a última menção de $\mathrm{BC}$ ao seu projeto de filme, espécie de pedido de socorro, lançado ao amigo mecenas pelo correio internacional.

Um ano depois, novamente no Brasil, Cendrars presencia a eleição de Washington Luís à presidência da República. Na terceira viagem, em 1927, passa toda a temporada no Rio de Janeiro, quando teria tido a oportunidade de visitar o amigo presidente no Palácio do Catete, mas não há documentação nesse sentido. Ele parecia na ocasião mais interessado em tipos populares -Donga, Febrônio-, e nas incursões nas favelas com a ambulância do pronto-socorro. $\mathrm{O}$ resto desta história é apenas literatura.

Do ponto de vista do cinema, o projeto é bastante esclarecedor, sobretudo de um profissionalismo de que até hoje se duvida. Cineasta sem filme, Cendrars conseguiu a proeza, desde os anos vinte, de se fazer passar por um "homem do ramo", constata desconfiado Claude Leroy. Para ele, esse cinema é apenas "de papel". " O único filme que dirigiu na Itália -La Venere Nera (A Vênus Negra)- fracassou na bilheteria e na crítica. ${ }^{12}$ Desse filme não restou cópia, mas $\mathrm{BC}$ publicou o seu roteiro -em que aliás revela pleno domínio do meio- com o título de La Perle Fiévreuse. Sua passagem pelo cinema, no entanto, costuma ser encarada como veleitária, amadorística, no que é confirmada pelo depoimento de Abel Gance:

ele permanecia estranho ao nosso trabalho, que o desorientava, que ele mal acompanhava [...] ele não tinha a minima experiência profissional...13

11. LEROY, Claude. La Main de Cendrars. Villeneuve d'Ascq (Nord): Septentrion, 1996, p. 219.

12. La Venere Nera recebeu certificado da censura italiana em janeiro de 1923. Críticas da época falaram em "tratamento banal", "interpretação mediocre", "absurda mistura de cenas sem sentido". Cf. PILARD, Philippe. "Cendrars: cinéma de rêve, rêve de cinéma", Blaise Cendrars, Sud, Marselha: 1988, p. 125.

13. CEuvres complètes de Blaise Cendrars, edição do Club français du livre, t. 2, p. $\mathrm{XX}$, citado por VANOYE, Francis, "Le cinema de Cendrars", Europe, Paris, jun. 1976, p. 185. 
Em 1918, Gance procurava veteranos de guerra para atuarem como figurantes na cena dos mortos que retornam das tumbas para assombrar os espectadores de seu filme J'accuse. Cendrars the é apresentado e logo se liga a ele por amizade. Torna-se seu assistente faz-tudo: contra-regra, eletricista, fogueteiro, figurinista, assistente de câmara, de direção, motorista, contador, caixa, figurante. [OCD8: 672-3] Dois anos depois, Gance vai chamá-lo para trabalhar em La Roue. A contribuição de Cendrars nesse filme é controvertida. Segundo Jean Epstein, a participação dele ficou restrita à filmagem e no âmbito de uma segunda unidade de produção. ${ }^{14}$ Ezra Pound, num artigo de 1923, atribui a BC os momentos interessantes e os efeitos propriamente cinematográficos de La Roue; o resto do filme é o "usual sentimentalismo imbecil". is

O próprio Cendrars parece concordar com Pound. Na sua correspondência com Jacques-Henry Lévesque em mais de uma ocasião refere-se a Gance de maneira pouco cordial. Numa delas sugere modificações num texto que Lévesque está escrevendo para insinuar exatamente o reconhecimento de sua contribuição:

O célebre filme silencioso La Roue de Abel Gance foi rodado em 1921-22 e fez sensação pelas cenas digamos em montagem simultânea do trem em velocidade! $O$ que acha? Seria forte demais?. [Carta de 9/5/43, OCD9: 190]

A insinuação maliciosa cede lugar, em carta posterior, a um ataque direto:

14. EPSTEIN, Jean. Écrits sur le cinéma. Paris: Seghers, 1974, t. 1, pp. 33 e ss, cit. por MOURIER, Maurice. "Quand Cendrars rêve cinéma...", Minard, série "Blaise Cendrars", vol. 1, p. 110.

15. "Thanks, we presume, to Blaise Cendrars, there are interesting moments, and efects which belong, perhaps, only to the cinema. At least for the sake of argument we can admit that they are essentially cinematographic. [...] and the rest of the show remains the usual drivelling idiocy of the cinema sentiment...". POUND, Ezra, "Panis letter", The Dial, março de 1923, cit. por LAWDER, Standish D., The Cubist Cinema. Nova York: New York University Press, 1975, p. 96. 
Acabei a revisão de Dan Yack (eliminei a dedicatória a Gance, na verdade [ele] não merece mais figurar no meu livro! Nem mesmo numa nota!). [Carta de 15/10/45, OCD9: 379-80]

Tal comportamento lança alguma luz sobre a postura de Cendrars no projeto do filme $100 \%$, no qual se apresenta como realizador de J'Accuse e de La Roue, feitos "em colaboração com Abel Gance". Considerava sua contribuição nesses filmes maior do que costumava ser admitida pelo companheiro, talvez por isso cometera a leviandade de inverter a ordem dos colaboradores.

Cendrars tinha uma posição ambígua diante do cinema. Como escritor, via a nova arte como um poderoso instrumento de revelação dos homens a si mesmos, a câmara de filmar como um bisturi nas mãos do cineasta-cirurgião - ele havia estudado medicina mas não concluiu o curso-, e as diferentes lentes da câmara de filmar, como pinças num laboratório. Seriam elas dotadas de capacidades extrafísicas; a lente 28 , por exemplo, "colore os pensamentos", a 12 , "penetra insensivelmente a sua vitima para roubar-lhe a personalidade" etc. [OCD7: 39-40; 42]

Já o cineasta queria distância da literatura. Cendrars mergulhara "de corpo inteiro no cinema" após "despedir-se da poesia" em $1917 .{ }^{16} \mathrm{O}$ cinema que fazia -ou que queria fazer- era popular, sentimental, vulgar, nos antípodas do "cinema puro", o único que o escritor valorizava. O cineasta fazia filme "para ganhar dinheiro"; para o escritor tudo faz prever que nos encaminhamos para uma nova sintese do espirito humano, para uma nova humanidade e que uma raça de homens novos vai surgir. Sua linguagem será o cinema!. [OCD4: 165]

O cineasta abraçava a física dos negócios; o escritor, para quem o cinema era uma nova religião, a metafísica da linguagem.

16. LEROY, Claude. Op. cit., p. 217. 
No projeto do filme de propaganda para o Brasil não há literatura. Ao contrário, o cineasta desconfia dos parceiros literatos Oswald e Washington Luís, incumbidos da sinopse e da redação romanceada do roteiro, e enfatiza sobretudo a questão da visualidade: "todas as situações dramáticas devem ser resolvidas ou desenredadas Visualmente" (o grifo é de $\mathrm{BC}$ ).

Entre os destaques do projeto está o planejamento da distribuição do filme, assim como a estratégia de sua exibição. De início localizada, para chamar a atenção do público, em seguida ampliando o circuito das salas, alude com certeza a experiências anteriores bem sucedidas. $O$ jogo com a mídia, as ressonâncias comerciais obtidas com a exploração da trilha sonora em concertos e do roteiro romanceado em forma de livro, a previsão de duas versões do filme destinadas a platéias distintas, o conjunto das ações propostas é astucioso e premonitório. Só faltou Cendrars inventar a distribuição de brindes e camisetas.

Do ponto de vista da produção, o projeto não é menos imaginoso. O filme deve ser "de exceção", isto é, deve destacar-se da produção média, para garantir o retorno do investimento. Há muito que se sabe que na indústria do cinema, como num jogo de azar, quanto maior a aposta crescem as chances de lucros fabulosos se o filme estourar na bilheteria. O risco é total pois nesse caso eliminamse as chances dos resultados medianos. Mas como o investimento seria composto de recursos privados (companhias distribuidoras, bancos), públicos (governos federal e estaduais), na proporção de $1: 2$, e Cendrars contabilizaria como investimento o seu capital profissional -seus dez anos de atividades cinematográficas e seu trabalho de criação-, o risco se dilui. Trata-se da clássica fórmula da co-produção entre países, pela qual os investimentos de cada país são aplicados no seu próprio território, sem necessidade de transferências internacionais de moeda. A distribuidora do filme retém as receitas de comercialização em escala mundial até se ressarcir do investimento, os governos obtêm o seu retorno institucional por meio da propaganda que o filme veicula, e Cendrars não põe um tostão do dinheiro - que aliás nunca teve- mas participa dos lucros. 
Nosso diretor/produtor introduz ainda um conceito que só se tornou corrente na indústria americana no decênio de 1950: a participação nas receitas do filme da equipe principal de criação, incluídos os autores do argumento, da trilha sonora, os atores, o fotógrafo etc. ${ }^{17}$

A ambigüidade escritor/cineasta retorna em outro plano. Cendrars no projeto ora se comporta como produtor, ora como diretor. Para o produtor, a execução de um filme de grande espetáculo segue uma espécie de receita de bolo: a "fórmula Superprodução". Por outro lado, querendo assegurar "o alcance Total do filme", Cendrars se reserva as funções de autor da decupagem e diretor. Inspirado em Griffith e Gance, também ele se vê como duplo de produtor e autor, de homem de negócios e artista.

Bem ao contrário do que afirma em "Etc..., etc..., Um filme $100 \%$ brasileiro", o projeto do filme não surgiu da espontaneidade de um encantamento com a beleza contagiante do país visitado - o "paraíso terreal" -, mas de uma intenção desapaixonada. Não digo que o encantamento não tenha ocorrido, mas o projeto de filme é anterior e dele mesmo prescinde. $\mathrm{O}$ que dá sustentação ao projeto é o seu lado oficial, Brasil "o maior país do futuro". A ingenuidade ou a intenção abertamente comercial de Cendrars provoca no leitor contemporâneo um sorriso irônico diante da frase

O Brasil é um Grande Estado Moderno com um passado, tradições, uma história. É atualmente uma grande República Democrática que oferece todas as garantias morais desse regime.

Em junho de 1924, o país vivia sob estado de sítio, decretado pelo governo de Artur Bernardes. E a revolução que eclodiria no mês seguinte denunciaria a democracia de fachada e a mão de ferro com que era conduzido. Mas estamos no domínio da propaganda, em que importam menos as qualidades do produto a ser vendido que a forma com que é feita. E Cendrars era um precursor no culto dessa nova forma de comunicação.

17. A elaboração do orçamento de um filme nos EUA utiliza duas fontes, separadas por uma linha. Below the line contabiliza as despesas de fabricação do produto, above the line, os direitos da equipe principal de criação, que dessa maneira participa em percentagem do resultado comercial do filme. 
Ao tomar partido numa polêmica que se desenrolaria em Paris em 1927 sobre a concessão de um prêmio à melhor peça publicitária feita por um escritor, dirá ele:

Publicidade = Poesia. A publicidade é a flor da vida contemporânea; é uma afirmação de otimismo e de alegria, ela distrai o olho e o espirito. É a mais calorosa manifestação da vitalidade dos homens de hoje, de seu poderio, de sua puerilidade, de seu dom de invenção $e$ de imaginação... [DIT: 57; OCD3: 229]

Outro ponto polêmico do projeto diz respeito à sua ancoragem histórica. Escolher um episódio da história paulista - o caso dos irmãos Lemes - pelo que ele oferece de conteúdo patriótico ao narrar uma luta de aventureiros pré-capitalistas que não se submetem ao jugo da metrópole, para defender a liberdade e sobretudo seus interesses econômicos, parece rico de significados. Mas afirmar que a "História Paulista se confunde tão freqüentemente com a História Nacional", revela antes uma posição do grupo a que Cendrars estava vinculado, composto de paulistões orgulhosos, chefiados por Paulo Prado. Assim, quando transformar o projeto do filme em literatura, Cendrars deixará de lado o episódio dos Lemes, tema do filme do cineasta, e se fixará na narrativa do capítulo "Pires e Camargos", de Paulistica, de autoria do amigo.$^{18}$ Lá encontrará os elementos dramáticos de uma vendetta que se desenrola ao longo de gerações, tema do filme do escritor.

O projeto do filme de propaganda afirma a certa altura que o cinema no Brasil não existe como indústria, só como comércio de fitas importadas. E que pretende dar um "impulso generoso" nessa indústria nascente. O método é o transplante de técnicos estrangeiros e de tecnologia (estúdios ambulantes) cujo domínio seria compartilhado com membros brasileiros da equipe profissional. ${ }^{19}$ Embora o

18. PRADO, Paulo. Paulistica. 2a. ed. aumentada. Rio de Janeiro: Ariel, 1934, pp. 65-88.

19. A visão "generosa" de Cendrars sobre o futuro do cinema brasileiro será reforçada num trecho de seu texto "Des hommes sont venus...", de Le Brésil 
diagnóstico estivesse correto - infelizmente continua correto ainda hoje--, o que autorizava o visitante a ignorar o medíocre Cinema Brasileiro?.

No grupo modernista apenas Mário de Andrade acompanhava o lançamento dos filmes nacionais. Mas as suas críticas eram publicadas sob pseudônimo, para não suscitar o deboche dos amigos que desprezavam os cavadores locais. ${ }^{20} \mathrm{~A}$ única manifestação conhecida de Paulo Prado sobre o assunto alude à praga que assolou o país: os "inúmeros cinemas que pululam como sanguessugas até os confins dos sertões". ${ }^{21}$ Contextualizando, essa crítica se dirige à exploração do mercado pelo filme estrangeiro, o que provoca sangria de divisas. Se Paulo Prado nunca se manifestou positivamente a favor da produção cinematográfica nacional, podemos inferir pelo comentário citado que apoiaria o estabelecimento dessa indústria e via com bons olhos a iniciativa de Cendrars e Oswald, embora pudesse criticar-lhe o seu aspecto ufanista.

A coincidência de pontos de vista entre Prado e Cendrars pode ser sentida numa declaração deste feita a Nino Frank:

...o Brasil está estourando de dinheiro. Os americanos, Ford e Hollywood, garfam tudo: só se pensa em automóveis. Cinemas em toda a parte. Lá corre um rio de dinheiro, que sobe em direção ao Norte. ${ }^{22}$

Oswald, desde 1922 com Os Condenados, tentava fazer cinema de palavras. Sua narrativa buscava a simultaneidade das ações paralelas, que o cinema depois de Nascimento de uma nação

(1952), em que diz: "...le Far-West d'un cinéma futur... quand le Brésil sera prêt à tourner et aura son Hollywood, Kinétopolis, studios et bungalows et gratte-ciel pour la telévision, et une tour d'émission pour la radio qui se dresseront aux confins du monde civilisé, en l'an 2000...". [BRE: XVI]

20. Depoimento de Rubens Borba de Morais em GALVÃO, Maria Rita Eliezer. Crónica do Cinema Paulistano, São Paulo: Ática, 1975, p. 43.

21. PRADO, Paulo. Retrato do Brasil. 8a. ed., São Paulo: Companhia das Letras, 1997, p. 205. Org: Carlos Augusto Calil.

22. Entrevista a Nino Frank, "Malles et valises", Les Nouvelles Littéraires, Paris, 21/4/28. Reproduzida em EULALIO, op. cit., p. 177. 
consagrara como uma marca registrada. Não se fizera ele passar certa vez por um cineasta em filmagem para com esse álibi raptar a bailarina adolescente Landa Kosbach, objeto de uma paixão incontrolável? ${ }^{23}$

Washington Luís, que não era propriamente um modernista, conhecia as potencialidades do cinema como propaganda política. Na presidência do Estado (1920-24) contratou por um conto de réis por mês um cinegrafista italiano -Gilberto Rossi- para que este apresentasse, em duas edições mensais, as Rossi Actualidades. Inicialmente a intenção do operador era filmar "cataratas, florestas virgens, praias e outras belezas naturais" para propaganda no estrangeiro. Mas "em vez disso [Rossi] filmava estradas e inaugurações". ${ }^{24}$

Fora do grupo diretamente envolvido no projeto do grande filme de propaganda, mas próximo de seus membros, merece ser lembrado Menotti del Picchia, o colunista "Helios" do Correio Paulistano. Modernista da primeira hora, era sócio de uma empresa de produção de cinema, a Independência Omnia Film, fundada por ocasião do centenário da Independência para realizar documentários.

Menotti, ligado ao partido do governo, o PRP - Partido Republicano Paulista, ajudava o irmão José (que tocava a produtora) a conseguir contratos oficiais para filmagem de "naturais". O próprio Menotti reconheceria mais tarde que esses "naturais" - nome que se dava aos documentários, por oposição aos "posados", os filmes de ficção - eram uma grande mamata. Sempre houve muita cavação no cinema, mas aquela era a maior de todas, a quinta-essência da cavação. ${ }^{25}$

Maria Rita Galvão, em Crônica do Cinema Paulistano, descreve esse universo de aventureiros que viviam precariamente de cinema:

23. Cf. ANDRADE, Oswald de. Um Homem Sem Profissão ("Sob as ordens de mamãe", memórias) e Memórias Sentimentais de João Miramar (ficção).

24. GALVÄO, Maria Rita Eliezer, op. cit., p. 198.

25. Idem, p. 254. 
Sob qualquer de suas formas, a cavação foi a base de sustentação do cinema paulista. Recorria-se a toda sorte de expedientes, nem sempre recomendáveis, para arrumar dinheiro [...] feito o filme, ao fim de cada experiência voltava-se à estaca zero, com a agravante de que, a cada fracasso, diminuía o crédito do cinema nacional e o número de candidatos a financiadores. ${ }^{26}$

As medidas propostas para combater a improvisação e implantar uma verdadeira indústria eram invariavelmente o investimento em equipamentos e estúdios e a importação de profissionais estrangeiros. Em 1924, ao mesmo tempo em que Cendrars planejava o seu filme, o ambiente cinematográfico de São Paulo era sacudido com o empreendimento de Adalberto da Almada Fagundes, industrial do ramo de porcelana, que criou em moldes grandiosos a Visual Film. Para dirigir o primeiro -e único- filme que produziu, Quando Elas Querem, foi buscar um técnico estrangeiro em Campinas, um italiano de nome Eugenio Centenaro, que se fazia passar por Eugene C. Kerrigan. ${ }^{27}$

A conviç̧ão de nossas elites de que cinema é coisa de estrangeiro é ainda anterior. Em 1918, o jornal O Estado de S. Paulo noticiava a chegada de um ilustre desconhecido, "o sr. Leon Bary, artista francês" que vinha "tratar de montar aqui, com capitais brasileiros, uma grande empresa cinematográfica". ${ }^{28} \mathrm{E}$ a Vera Cruz, no decênio de 1950, irá repetir a receita da Visual, equipamentos e técnicos estrangeiros, com resultados igualmente frustrantes, pela mesma ausência de estrutura de comercialização.

Cendrars, poeta pranteado, não circulava fora dos meios literários; era refém dos intelectuais que o hospedavam. Não deve ter tomado conhecimento da iniciativa de Almada Fagundes, que corria paralela à sua. Uma eventual associação de interesses convergentes

26. Ibidem, p. 53.

27. Ibidem, p. 55.

28. O Estado de $S$. Paulo, $4 / 9 / 18$, cit. em BERNARDET, Jean-Claude. Cinema Brasileiro: Propostas para uma História, Rio de Janeiro: Paz e Terra, 1979, p. 32. 
poderia ter transformado ambas as experiências ou mesmo as convertido num mesmo empreendimento, com a vantagem de aproximar capitais nacionais disponíveis de um projeto $\multimap$ do filme de propaganda-que, embora megalômano, tinha uma perspectiva de mercado.

Na sua nova pele de cineasta, Cendrars demonstra uma segurança que impressiona, mesmo se relevarmos uma ponta de cabotinismo. No projeto ele se descreve como

alguém do ramo, conhecedor de todos os recursos de sua arte, dos truques da técnica, das necessidades comerciais e do gosto dos diferentes públicos do mundo [...] um fino psicólogo e dotado do sentido da realidade....

Num livro inconcluso, escrito no Brasil e que permaneceu inédito até recentemente, proclama-se um perito, capaz de lidar com "as prevenções dos sócios investidores e dos exibidores, a sentimentalidade dos espectadores, todas essas coisas primárias e besteiras convencionais..." [JPJ: 97]

De nada lhe serviriam tantos atributos. Por que fracassou o projeto do filme $100 \%$ brasileiro de Cendrars? Foi a embrulhada com os outros negócios de Oswald, conforme se queixaria a Paulo Prado? E o cineasta não se dava conta de que enquanto buscava qualificarse "profissionalmente" para um projeto de tamanha envergadura que teria mudado o curso da sua vida, associava-se a dois diletantes, Oswald de Andrade e Washington Luís, sem problemas de sobrevivência, cujos interesses prioritários estavam plantados em outros campos?

Oswald permanecerá ligado ao cinema, ao menos no plano virtual. Escreveu diversos roteiros, nenhum chegou a ser filmado. "Perigo negro", extraído do seu romance Marco Zero, foi publicado na Revista do Brasil, em 1938. ${ }^{29}$ Por essa época, tentou obter

29. Revista do Brasil, 3a. fase, ano I, no. 4, Rio de Janeiro: out. 1938, pp. 383-417. 
... um contrato com o Ministério da Agricultura, Indústria e Comércio visando à realização de um "grande filme de propaganda nacional". Pretendia divulgar nos Estados e no estrangeiro as diversas feições da vida brasileira, da sua história, e do seu progresso atual, com ênfase no desenvolvimento do espirito criador. O plano privilegiava dois grandes aspectos do país: a formação geográfica $e$ econômica, uma vez que o empreendimento cinematográfico se comprometia a divulgar o investimento nesses setores por parte do governo federal. Esse foi outro projeto que não saiu do papel, apesar do ministro Marcondes $M$. Filho ser seu amigo. ${ }^{30}$

Aí está a evidência de que o projeto do "grande filme de propaganda" era idéia de Oswald, que não a tendo podido viabilizar em 1924, insistia novamente no final dos anos 30. Dele falara com Blaise ainda em Paris, tentando atraí-lo para uma viagem ao Brasil. Por esse motivo, Cendrars ao escrever à família, nas vésperas do embarque, mencionava negócios que lhe haviam sido propostos, "sendo um de cinema que pode ser muito interessante".

Contrariando as expectativas do visitante que acolhia, o Brasil não lhe permitiu concretizar nenhuma das inúmeras oportunidades de negócios com que sonhara fazer a América. Dessa experiência, Cendrars sairá traumatizado e cunhará uma frase, repetida ao longo de sua obra futura, que intriga o leitor pelo conteúdo emblemático que encerra, para além do simples paradoxo: "les affaires ne sont pas les affaires" ("negócios que não são negócios"). ${ }^{31}$

Mais tarde, quando foi capaz de elaborar o malogro, Cendrars, ao admitir que o Brasil enquanto lhe negava o sucesso nos negócios, inclusive a grande virada na sua carreira de cineasta, inspirara-lhe o dom de escrever "romances", que soube capitalizar com L'Or e Moravagine.

30. BOAVENTURA, Maria Eugênia. O Salão e a Selva. São Paulo; Campinas: Ex Libris; Editora da Unicamp, 1995, pp. 177; 194.

31. Cf. V. Rhum, OCD3: 294-96; Bourlinguer, OCD6: 42; Une Nuit dans la Forêt, OCD7: 23 , com a variante: "Non, les affaires sont dures." 
Escrevera Ouro em seis semanas, tão impaciente estava eu por partir de novo para o Brasil, onde me esbaldava em perder meu tempo, como no ano anterior, por ocasião da revolução de Isidoro, em que não tinha escrito uma linha sequer...

Foi assim que me iniciei, não tanto na arte do romance como na arte do... capitão de indústria que o romancista moderno pósBalzac exerce e que consiste em saber descolar dinheiro na volada. [Moravagine, Pro domo, OCD2: 440]

A cavação, como se pode constatar, nem é exclusividade do cinema, nem dos cineastas brasileiros. Os projetos de Blaise no cinema inviabilizaram-se de uma forma ou de outra. Por que a insistência dele em recomeçar? Para se libertar do ofício de escrever - que considerava mais conforme a um burocrata, alguém que renuncia à vida -; para mergulhar na ação, na agit[ação], porque "fazer cinema é uma paixão, como um pico de morfina. Uma vez que se experimentou, não há meio de abandonar." [DIT: 50]

Anos mais tarde, quando trabalhava na decupagem para um filme baseado em Victor Hugo, dirá numa carta a Paulo Prado: "Espero continuar algum tempo no cinema. É mais divertido e paga um bom bife!" 32

Desapontado, Cendrars teve de retornar à literatura. E na cozinha do escritor os textos são ora requentados, ora reformados, ou simplesmente remanejados. Remexendo velhos papéis ele se depara com o projeto do filme brasileiro. Com uma ponta de amargura lhe vem à memória a história desse filme cuja realização o levou ao Brasil. Lá sua vida tomou um rumo que não esperava. Lê o projeto. A quantidade de etc. nele empregada desperta sua curiosidade. Começa a contar, perde o número quando já passam de vinte. Há também alguns duplos: etc., etc... Mansamente chega-lhe a idéia para mais uma "histoire vraie". Ele se constrói um entrecho, mais generoso que o fornecido pela lembrança vívida da revolução de Isidoro, de Washington Luís, o amigo presidente, das trapalhadas de Oswald, uma história cuja inverosimilhança absolve a frustração.

32. Carta de 26 de agosto de 1933. 
Verdadeira no essencial, abriga no seu auto-irônico etc..., etc... tudo o que a aventura brasileira lhe sonegou.

\section{Bibliografia}

CENDRARS, Blaise. Euvres complètes. Paris, Denoël.

Tomo 2. - La Fin du Monde (O Fim do Mundo). L'Eubage (O Eubagem). L'Or (Ouro). Moravagine. Petits Contes Nègres (Historinhas Negras). 1961, 528 p. [OCD2]

Tomo 3 - Le Plan de l'Aiguille (O Plaino da Agulha). Confessions de Dan Yack (Confissões de Dan Yack). Rhum (Rum). Histoires Vraies (Histórias Autênticas). 1960, 458 p. [OCD3]

Tomo 4 - La Perle Fiévreuse (A Pérola Febril). Moganni Nameh. Comment les Blancs sont d'Anciens Noirs (De Como os Brancos São Primitivos Negros). Aujourd'hui (Hoje). Vol à Voile (Vôo a Vela). Panorama de la Pègre (Panorama do Submundo). Hollywood, la Mecque du Cinéma (Hollywood, a Meca do Cinema). La Vie Dangereuse (O Risco da Vida). 1962, 592 p. [OCD4]

Tomo 6 - Bourlinguer (Vagamundear). Le Lotissement du Ciel (O Loteamento do Céu). 1961, 612 p. [OCD6]

Tomo 7 - Une Nuit dans la Forêt (Uma Noite na Floresta). Chez l'Armée Anglaise (Com o Exército Britânico). La Banlieue de Paris (A Periferia de Paris). Emmène-moi au Bout du Monde!... (Arrasta-me Até o Fim do Mundo!...). 1964, 408 p. [OCD7]

Tomo 8 - D'Oultremer à Indigo (Do Ultramar ao Índigo). Trop, C'est Trop (É Demais, Demais). Films Sans Images (Filmes Sem Imagens). Textes inédits en volumes (Textos inéditos em volume). Blaise Cendrars Vous Parle... (Com Vocês, Blaise Cendrars...), entrevistas concedidas a Michel Manoll. "Bibliographie générale" (Bibliografia geral), por Hughes Richard. 1965. 780 p. [OCD8]

Tomo 9 - "J'écris. Écrivez-moi.". ("Escrevo. Escreva-me.") Correspondance Blaise Cendrars - Jacques-Henry Lévesque 1924-59. CHEFDOR, Monique (org.). 1991, 648 p. [OCD9] 


\section{Outras obras de Blaise Cendrars:}

Le Brésil. Texto de $\mathrm{BC}$, fotografias de Jean Manzon. Mônaco: Les documents d'art, 1952. [BRE]

Dites-nous, Monsieur Blaise Cendrars. RICHARD, Hughes (org.). Lausanne: Rencontre, 1969. [DIT]

John Paul Jones ou l'Ambition. LEROY, Claude (org.). [Montpellier]: Fata Morgana, 1989. [JPJ] 